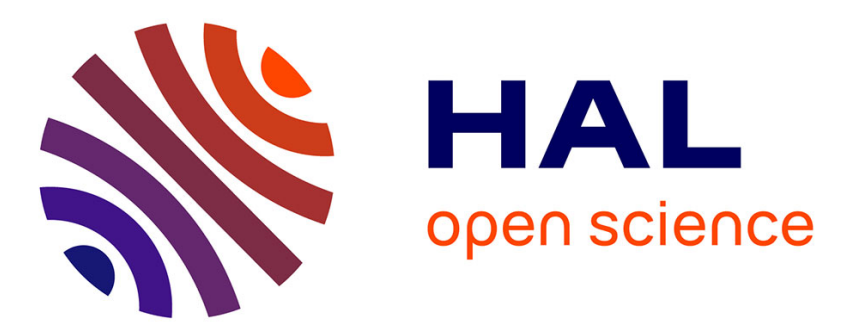

\title{
Social and emotional cognition in patients with severe migraine consulting in a tertiary headache center: a preliminary study
}

Margaux Bouteloup, Rose-Angélique Belot, Nicolas Noiret, Géraldine Sylvestre, Maxime Bertoux, Eloi Magnin, Fabrice Vuillier

\section{To cite this version:}

Margaux Bouteloup, Rose-Angélique Belot, Nicolas Noiret, Géraldine Sylvestre, Maxime Bertoux, et al. Social and emotional cognition in patients with severe migraine consulting in a tertiary headache center: a preliminary study. Revue Neurologique, 2021, 10.1016/j.neurol.2020.09.013 . hal-03110207

\section{HAL Id: hal-03110207 \\ https://hal.science/hal-03110207}

Submitted on 14 Jan 2021

HAL is a multi-disciplinary open access archive for the deposit and dissemination of scientific research documents, whether they are published or not. The documents may come from teaching and research institutions in France or abroad, or from public or private research centers.
L'archive ouverte pluridisciplinaire HAL, est destinée au dépôt et à la diffusion de documents scientifiques de niveau recherche, publiés ou non, émanant des établissements d'enseignement et de recherche français ou étrangers, des laboratoires publics ou privés. 
Title: Social and emotional cognition in patients with severe migraine consulting in a tertiary headache center: a preliminary study

\section{Authors}

Margaux Bouteloup ${ }^{1}, \mathrm{PhD}$, margaux.bouteloup@live.fr (ORCID: 0000-0001-7834-1081)

Rose-Angélique Belot ${ }^{1}$, Associate professor, rose-angelique.belot@univ-fcomte.fr

Nicolas Noiret ${ }^{2}$, Visiting associate professor, nicolas.noiret@univ-tours.fr

Géraldine Sylvestre ${ }^{3}$, Neuropsychologist, sylvestre.geraldine@gmail.com

Maxime Bertoux ${ }^{4}, \mathrm{PhD}$, Senior Research Scientist, Neuropsychologist, maximel.bertoux@gmail.com

Eloi Magnin ${ }^{56}$, Professor, Neurologist, eloi.magnin@laposte.net

Fabrice Vuillier ${ }^{56}$, Professor, Neurologist, fabrice.vuillier@univ-fcomte.fr

${ }^{1}$ Laboratory of Psychology EA3188, University of Franche-Comte, 30-32 Rue Megevand, 25030 Besancon, France.

${ }^{2}$ UMR 7295 « Centre de Recherches sur la Cognition et l'Apprentissage », CNRS, Université de Tours et Université de Poitiers, France.

${ }^{3}$ Memory Center of Research and Resources (CMRR), University Hospital of Besançon, France. 2. Department of Neurology, University Hospital of Besançon, France.

${ }^{4}$ Lille Neuroscience \& Cognition, Inserm U1172, Univ Lille, University Hospital of Lille, France.

${ }^{5}$ Laboratory of Neurosciences, EA 481, University of Bourgogne Franche-Comté, Besançon, France.

${ }^{6}$ Department of Neurology, Regional University Hospital of Besançon, 2 Boulevard Fleming, 25000 Besançon, France 


\section{Corresponding author}

Margaux Bouteloup

87 rue des Granges

25000 Besançon

France

margaux.bouteloup@live.fr

Authorship: MBo participated in setting and planning the research project, data collection, data analysis, and writing of the article. RAB and FV in setting up and planning the research project, data collection, and writing of the article. GS, NN, MBe and EM participated in data analysis and writing of the article. 
Title: Social and emotional cognition in patients with severe migraine consulting in a tertiary headache center: a preliminary study

\begin{abstract}
Twenty-three severe migraine participants were studied to investigate social and emotional cognition features and explore their relationship with depression, anxiety and alexithymia. In comparison to normative data, $74 \%$ were under the norm for the Faux Pas subtest, $13 \%$ for the facial emotion recognition subtest and $52 \%$ for the overall composite score of the miniSEA. Factor 1, Factor 3, and the total score of the TAS-20 were negatively correlated with the Faux Pas subtest. Our preliminary study shows that severe migraine patients present difficulties in inferring mental states, which could be related to alexithymia. It would be useful to identify these impairments in order to improve the quality of care provided.
\end{abstract}

Clinical Trials registration number: NCT03577548

Key Words: Headache - Theory of Mind - Mentalization - Psychological factors Alexithymia 


\section{Introduction}

In literature, migraine is often associated with psychological factors such as anxiety, depression, and stress [1]. The presence of alexithymia in migraine patients has also been reported increasingly frequently in recent years. Alexithymia-defined as difficulty in expressing feelings in words and in experiencing symbolic thought - seems to be related to the intensity and frequency of migraines, as well as how they are triggered and how disabling they are [2-3]. Regardless of the severity of migraine, alexithymia appears to be a psychological characteristic of migraine patients [4].

Alexithymia is associated with deficits in recognizing facial emotion and inferring mental states [5]. This latter ability, also called "theory of mind", refers to the capacity to mentalize one's own thoughts, beliefs, and mental states as well as those of others. Both emotion recognition and mental state inference are key dimensions of cognition and have been shown to be important determinants of quality of life, well-being, and daily functioning [6]. Although several studies have been conducted in children with migraine, showing the presence of social cognition impairments [7], few studies have investigated social cognition in adult migraine patients. Emotion recognition and mental state inference have been shown to be associated with a higher rate of depression and medication overuse in patients with chronic — but not episodic - migraine [8]. However, the relationship between social cognition, alexithymia, and psychological states in migraine patients remains unclear, although it would be reasonable to expect an association between these factors. Moreover, the strong relationship found between alexithymia and social cognition abnormalities leads us to suggest that severe migraine could be also associated with a deficit in social cognition. 
The aim of the present study was to investigate the most common social and emotional cognition dimensions in patients presenting with severe migraine at a tertiary headache center. Another objective of our study was to explore the relationship between social and emotional cognition, depression, anxiety, stress, and alexithymia.

\section{Materials and methods}

Our study was approved by the clinical ethics committee of Besançon Regional University Hospital (CHRU) and has been registered in Clinical Trials (NCT: 03499392). All patients gave their written informed consent before inclusion.

\subsection{Participants}

The patient cohort described in this paper is taken from a larger observational study conducted at the tertiary headache center of the Besançon CHRU neurology department. We included patients with episodic migraine with/without aura, or chronic migraine with/without medication overuse, according to the new International Classification of Headache Disorders criteria (ICHD-III beta version). We excluded all patients with a history of psychiatric disorder, previous or current neurological disease, or who were pregnant. We evaluated migraine-related disability using the French version of the Headache Impact Test (HIT-6) and

\section{collected the number of attacks per month.}

In contrast to the larger-scale study, only patients consulting for the first time $(N=32)$ were evaluated for social and emotional cognition. Nine participants were excluded from this initial sample because of an unclear diagnosis $(n=2)$ or missing data $(n=7)$. The statistical analyses presented below are therefore based on the final sample of 23 patients (age range: $26-58$ years). No patient experienced a migraine attack during the assessment. All patients were autonomous, had a professional activity, and presented no cognitive complaints. 
Patients were compared to 30 control participants from the normative age-matched sample (age range: 28-50 years) of the mini-Social Cognition and Emotional Assessment (miniSEA). These control participants were all assessed at the Pitié-Salpêtrière hospital (in a relevant study approved by the Pitié-Salpêtrière ethics committee) and presented no cognitive decline/complaint and no depression/anxiety. See [9] for details about inclusion criteria.

\subsection{Materials}

The mini-Social Cognition and Emotional Assessment (mini-SEA) [9] is a neuropsychological test battery that briefly assess two key components of social and emotional cognition through two subtests:

- The facial emotion recognition (FER) test, which is scored from 0 to 15 , in which participants select from a list which emotion is being expressed by 35 unknown faces (happiness, surprise, neutral, sadness, disgust, anger, and fear);

- The shortened and modified Faux Pas (mFP) test, scored from 0 to 15, involves 10 short stories in which the participants have to detect social faux pas and infer the intentions and feelings of the stories' characters.

The overall mini-SEA composite score was calculated by adding the two subscores, and was scored from 0 to 30 .

In addition to these assessments, the migraine patient group also completed the following selfadministered questionnaires:

- The Toronto Alexithymia Scale (TAS-20): a 20-item self-report scale that is one of the most commonly used measures of alexithymia [10]. The TAS-20 has three subscales: (1) Difficulty identifying feeling; (2) Difficulty describing feelings; (3) Externally- 
oriented thinking. TAS-20 cutoff scoring was used to determine the absence (score $\leq 44$ ), possible presence (45 to 55$)$, or confirmed presence $(\geq 56)$ of alexithymia.

- The shortened Beck Depression Inventory (BDI): a 13-item self-report scale that measures the presence and severity of cognitive, affective, and physiological symptoms of depression [11].

- The State-Trait Anxiety Inventory (STAI), which assesses anxiety level based on state (A-state) and trait (A-trait) anxiety [12].

- The Cungi Scale: a questionnaire evaluating the perception of stressors and level of stress [13].

\subsection{Statistical analysis}

Group comparisons (migraine patients vs control participants) were carried out using the Chisquare non-parametric statistical test for sex and educational level variables, and using the non-parametric Mann-Whitney test for the other variables. We calculated effect sizes using Cohen's $d$ for each group comparison. We also compared the proportion of patients who were under the mini-SEA norms with those over the norms. We compared detailed scores from the mFP questions using non-parametric Friedman ANOVA, with Durbin-Conover pairwise comparisons as follow-up analysis. Finally, for the patient group only, we performed partial correlation analyses between mini-SEA scores and the other psychological scales (i.e. HIT-6, BDI-II, STAI, TAS-20 \& Cungi's scales), controlling for age and level of education (two variables known to influence mini-SEA performances) [9]. 


\section{Observation}

\subsection{Participants' characteristics}

Table 1. Mean (standard deviation) and statistical analyses for demographic data for migraine patients and control participants

\begin{tabular}{lccccc}
\hline \multicolumn{2}{c}{ Migraine } & & & & \\
Characteristic & patients & Controls & $\chi^{2}$ & $\boldsymbol{U}$ & $\boldsymbol{p}$ \\
\hline Sex (F/M) & $19 / 4$ & $15 / 15$ & 6.02 & .01 \\
Age & $42(8.71)$ & $40(6.09)$ & 299 & .41 \\
Educational level (years) & $14.04(2.63)$ & $12.70(2.97)$ & 243 & .11 \\
Middle school education (\%) & $13 \%$ & $30 \%$ & 2.15 & & .34 \\
$\quad$ High school education (\%) & $30 \%$ & $23 \%$ & & & \\
$\quad$ Graduate education (\%) & $57 \%$ & $47 \%$ & & & \\
\hline
\end{tabular}

Note: Educational level scale was built as follows: the first line corresponds to the number of years passed in the educational system; middle school education refers to participants whose highest academic qualification was the "Diplôme National du Brevet" (normally taken at age 15); high school education refers to participants whose highest academic qualification was the "baccalauréat" (normally taken at age 18); graduate education refers to participants who had a higher education qualification.

Patients' and control participants' demographic data is shown in Table 1. No significant difference in age or level of education was observed between migraine patients and control participants. In contrast, the distribution of men and women is significantly different. This was expected because in the population of people with migraines, the sex ratio is approximately three women to one man. The difference between the two groups in terms of 
the sex ratio does not affect the comparison of mini-SEA performance, because the mini-SEA is sensitive to age and level of education but not to sex [9].

Psychological characteristics and migraine impact of migraine are presented in Table 2 . The HIT-6 mean score and number of attacks per month showed that migraine has a severe impact on daily life. Because we recruited our participants in a tertiary headache center, our study population is specific and does not necessarily represent the general migraine population. However, it is necessary to explore the characteristics of this population because it represents patients who do seek neurological consultations.

The mean scores for stress and anxiety are high and the majority of patients had symptoms of depression (BDI). According to the TAS-20 score, $43.5 \%$ of the migraine patients had alexithymia.

Table 2. Mean (standard deviation) for migraine impact and psychological scales in sample of migraine patients.

Scales

$(\mathbf{N}=23)$

HIT-6: mean \pm SD

Number of attacks per month: mean \pm SD

\section{Distress (Cungi)}

Score: mean $\pm \mathrm{SD}$

$36.17 \pm 7.96$

\section{Anxiety (STAI)}

State score: mean $\pm \mathrm{SD}$

$54.87 \pm 10.52$

Trait score: mean \pm SD

$51.09 \pm 10.20$

\section{Depression (BDI)}

Mild depression

$30 \%$ 
Moderate depression

Severe depression

$10 \%$

\section{Alexithymia (TAS20)}

Factor 1 (identifying feeling) : mean \pm SD

$14.43 \pm 5.02$

Factor 2 (describing feeling) : mean \pm SD

$15.26 \pm 5.65$

Factor 3 (externally oriented thinking) : mean \pm SD

$18.39 \pm 4.27$

Total: mean \pm SD

$50.74 \pm 14.03$

No alexithymia

$39.1 \%$

Possible alexithymia

$17.4 \%$

Alexithymia

$43.5 \%$

Notes. BDI: Beck depression inventory; STAI: State-Trait

Anxiety Inventory; TAS: Toronto Alexithymia Scale

\subsection{Mini-SEA results}

Table 3. Mean (standard deviation) for the mini-SEA overall and subtest scores for migraine patients and control participants

\begin{tabular}{|c|c|c|c|c|c|}
\hline Mini SEA & Migraine patients & Controls & $\boldsymbol{U}$ & $p$ & $d$ \\
\hline Overall composite score & $22.75(3.12)$ & $26.35(1.87)$ & 101 & $<.001$ & 1.48 \\
\hline mFP subtest score & $10.42(2.04)$ & $13.83(1.34)$ & 59 & $<.001$ & 2.07 \\
\hline FER subtest score & $12.34(1.69)$ & $12.53(1.15)$ & 342 & $=.96$ & 0.14 \\
\hline \multicolumn{6}{|c|}{ Notes. FER: facial emotion recognition; mFP: modified Faux Pas; mini-SEA: mini-Social } \\
\hline \multicolumn{6}{|c|}{ Cognition and Emotional Assessment } \\
\hline \multicolumn{6}{|c|}{ The mini-SEA composite score was significantly lower for the severe migraine group than for } \\
\hline \multicolumn{6}{|c|}{ the control group (Table 3). This difference was driven by the mFP score, which was } \\
\hline
\end{tabular}


In our comparison with the normative data [9], 74\% of migraine patients were under the norm for the Faux Pas subtest, 13\% for the FER subtest and 52\% for the overall composite score.

Table 4. Details of the answers for the mFP subtest - migraine patient group

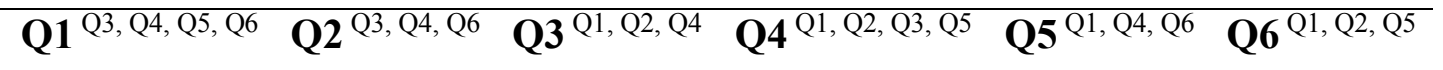

\begin{tabular}{cccccccc}
\hline & $\mathbf{5 / 5}$ & 8 & 8 & 1 & 0 & 2 & 1 \\
Number of & $\mathbf{4 / 5}$ & 6 & 6 & 8 & 1 & 8 & 6 \\
subjects & $\mathbf{3 / 5}$ & 6 & 5 & 5 & 5 & 8 & 5 \\
with a & $\mathbf{2 / 5}$ & 3 & 3 & 7 & 9 & 5 & 6 \\
score of & $\mathbf{1 / 5}$ & 0 & 1 & 2 & 8 & 0 & 4 \\
& $\mathbf{0 / 5}$ & 0 & 0 & 0 & 0 & 0 & 1 \\
\hline Mean score (SD) & $3.83(1.07)$ & $3.74(1.21)$ & $2.96(1.11)$ & $1.96(0.88)$ & $3.30(0.93)$ & $2.61(1.31)$
\end{tabular}

Note $: Q 1=$ Detected Faux Pas / Q2 = who made the Faux Pas / Q3 = explanation of the Faux Pas / Q4 = intentionality / Q5 = confirmation that the Faux-Pas is not intentional / Q6 = empathy. Mean scores for a series of control questions was 19.57/20. Exponents next to columns titles represent statistically significant differences with other questions (Durbin-Conover pairwise comparisons, $p<.001)$.

\subsection{Correlations between mini-SEA scores and other psychological scales}

Table 4 presents details of the migraine patients' scores for the Faux Pas stories. Friedman ANOVA revealed a statistically significant difference between questions, $\chi^{2}(5)=69.5, p<$ .001. Intentionality and empathy appear to be the two most impaired traits: of the 23 participants, 17 had a score of two or less for the question measuring intentionality (Q4) and 11 out of 23 participants had a score of two or less for the question measuring empathy (Q6). 
Table 5. Partial correlations for the social \& emotion cognition performance and the psychological scores for patients, controlling for age and educational level.

\begin{tabular}{lcc}
\hline Psychological scales & mFP & FER \\
\hline HIT-6 & -.29 & -.30 \\
Cungi's scale & -.22 & .09 \\
BDI-II & .06 & -.07
\end{tabular}

STAI

$\begin{array}{lll}\text { Trait } & -.12 & -.07 \\ \text { State } & .12 & -.17\end{array}$

TAS-20

$\begin{array}{rrr}\text { Factor } 1 \text { (identifying feeling) } & -.51^{*} & -.32 \\ \text { Factor } 2 \text { (describing feeling) } & -.27 & -.12 \\ \text { Factor } 3 \text { (externally oriented thinking) } & -.45^{*} & -.006 \\ \text { Total } & -.47^{*} & -.21\end{array}$

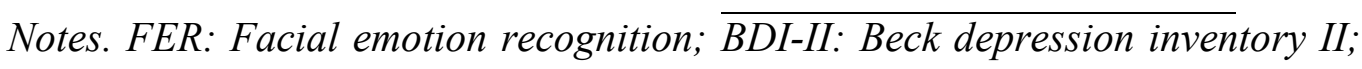

STAI: State-Trait Anxiety Inventory; TAS-20: Toronto Alexithymia Scale. *: $p<$ .05

Finally, correlations between the mini-SEA scores and the other scale scores are presented in Table 5. There was no correlation between the TAS-20 and FER subtests, but the mFP subtest was negatively correlated with Factor 1, Factor 3, and the total score from the TAS-20 questionnaire, which measures alexithymia. The other psychological scale scores (Cungi, BDI and STAI) and the headache impact and severity score (HIT-6) did not correlate with the mini-SEA scores. 


\section{Discussion}

In this study, we evaluated two key dimensions of social cognition in severe migraine patients, namely FER and mental state inference. While patients' FER performance did not differ from that of the control group, they did obtain significantly lower mFP scores than the control group. Indeed, $74 \%$ of severe migraine patients obtained a score lower than the established standard [9]. Interestingly, a high proportion of alexithymia was found in the patient group, $43.5 \%$ of whom had a TAS-20 score higher than 55 . This, although expected, is a relatively high percentage compared to that of the general population $(20.7 \%$ of the French population) or to past studies on migraine [2-3]. Additionally, even though our group was composed of patients with severe migraine, their levels of distress and anxiety were comparable to those of patients with classic migraine [1]. On the other hand, a little over half of our patients presented with emotional suffering according to the depression score. This proportion is higher than that of a classic migraine population [1]. In literature, it has been shown that alexithymia affects self-reflection and insight, and was related to higher levels of depression and anxiety in a group of migraine patients [2]. However, our results did not show correlation between level of depression and social cognition. Our overall observation was therefore that patients with severe migraine who consult in a tertiary headache center and present emotional suffering also have difficulties with social and emotional cognition.

This study also explored the correlation between psychological factors, headache severity, and the mini-SEA scores. We observed a negative correlation between the mFP subtest and the Factor 1, Factor 3, and total scores for the TAS-20 questionnaire. This suggests that the greater the severity of alexithymia (meaning that patients have difficulty identifying and describing their own mental states), the greater the difficulty in recognizing social faux pas and inferring others' intentions and emotions. This link has already been highlighted in 
literature [5-14]. It should be noted that the mean score for the mFP control questions, which aim to assess the general understanding of the stories, was near the optimal score, thus ruling out the possibility that comprehension problems caused the poorer performance in this test. Moreover, understanding of the social rules appears to be integrated; migraine patients were able to detect the faux pas and who made it (Q1, Q2), but they had difficulty explaining it in more depth. They failed in the inference of others' mental states: why did the person do that (Q4)? How does the other person feel (Q6)?

More precisely, statistical analysis of Factor 1 of the TAS-20 confirmed difficulties for migraine patients in mentalizing emotional and mental states for themselves and others. Correlation between Factor 3 of the TAS-20 and the mfP score confirms the difficulty in having a reflective position: thinking is practical and externally oriented. Severe migraine patients are more focused on the external outcomes than on feelings or intentions, even though they are able to describe them (Factor 2). We hypothesized that these poor performances could be linked to a lack of ability or desire to explore mental states in the context of persistent pain such as migraine [15].

The difficulties in inferring others' mental states that severe migraine patients experience should not be neglected in psychological and medical practice, as this could have a significant impact on the patient's social life, whether in a work or family context. This egocentrism could be a compensatory mechanism associated with the severity of the symptomatology. As the high HIT-6 scores suggest, our patient group is comparable to a population presenting a chronic pain syndrome. We hypothesize that people who experience too much physical pain in addition to emotional suffering will not be able to easily focus their attention on another person's mental state. Future studies should therefore investigate how attention and social cognitive performance interact in severe migraine. They should also explore the impact of 
medication on social cognition difficulties as well as alexithymia, as we currently cannot determine whether the diverse treatments (ranging from SSRI to opioid) have a negative or positive impact for patients on these particular points. Finally, the findings of this study, together with previous results showing that social cognition is a predictor of well-being and quality of life [16], highlight the potential for social cognition tests to serve as outcome measures for cognition in therapeutic interventions for migraine. From this perspective, a quick but multi-dimensional battery such as the mini-SEA could be useful, especially as a new class of treatments (i.e. monoclonal antibody treatments) should be available in trials soon.

\section{Conclusion}

In this study, severe migraine patients presented an isolated difficulty in inferring mental states, which may be linked to alexithymia. Identifying these impairments is relevant to patient treatment as well to their personal life. If psychological and medical treatments are unsuccessful in helping patients to moderate these social cognitive difficulties, cognitive rehabilitation workshops or psychoeducation could be used, with the aim of increasing the understanding of such difficulties and their potential impact for patients. For example, an innovative approach with an intensive social cognition intervention is currently used in patients with treatment-resistant chronic pain, and improves these patients' health-related quality of life. The same approach could be proposed for severe migraine patients consulting in a tertiary headache center. This more integrative management of symptoms should help severe migraine patients to increase their quality of life and well-being in their social lives, both in the private and professional spheres. 


\section{Declarations of conflicting interests}

The authors declare no potential conflicts of interest with respect to the research, authorship, and/or publication of this article.

\section{Funding}

This research did not receive any specific grants from funding agencies in the public, commercial, or not-for-profit sectors.

\section{Acknowledgements}

We would like to express our very great appreciation to Jennifer Dobson for proofreading our manuscript.

\section{References}

[1] Lantéri-Minet M, Radat F, Chautard M-H, Lucas C (2005) Anxiety and depression associated with migraine: Influence on migraine subjects' disability and quality of life, and acute migraine management. Pain 118(3):319-26. doi: 10.1016/j.pain.2005.09.010

[2] Yalınay Dikmen P, Onur Aysevener E, Kosak S, Ilgaz Aydınlar E, Sağduyu Kocaman A (2017) Relationship between MIDAS, depression, anxiety and alexithymia in migraine patients. Acta Neurol Belg. doi: 10.1007/s13760-017-0856-x.

[3] Neyal Muftuoglu M, Herken H, Demirci H, Virit O, Neyal A (2004) Alexithymic features in migraine patients. Eur Arch Psychiatry Clin Neurosci 254(3). doi: 10.1007/s00406-0040466-5

[4] Galli F, Caputi M, Sances G, Vegni E, Bottiroli S, Nappi G, et al (2017) Alexithymia in chronic and episodic migraine: a comparative study. J Ment Health 26(3):192-196. doi: 
$10.3109 / 09638237.2015 .1124404$

[5] Lane RD, Hsu C-H, Locke DEC, Ritenbaugh C, Stonnington CM (2015) Role of theory of mind in emotional awareness and alexithymia: Implications for conceptualization and measurement. Conscious Cogn 33:398-405. doi: 10.1016/j.concog.2015.02.00

[6] Henry JD, von Hippel W, Molenberghs P, Lee T, Sachdev PS (2016) Clinical assessment of social cognitive function in neurological disorders. Nat Rev Neurol 12(1):28-39. doi: 10.1038/nrneurol.2015.229

[7] Faedda N, Natalucci G, Calderoni D, Cerutti R, Verdecchia P, Guidetti V (2017) Metacognition and Headache: Which Is the Role in Childhood and Adolescence? Front Neurology 8:650. doi: 10.3389/fneur.2017.00650

[8] Gómez-Beldarrain M, Carrasco M, Bilbao A, García-Moncó JC. Orbitofrontal dysfunction predicts poor prognosis in chronic migraine with medication overuse. The Journal of Headache and Pain 2011;12(4):459-66.

[9] Bertoux M, Delavest M, de Souza LC, Funkiewiez A, Lépine J-P, Fossati P, et al (2012) Social Cognition and Emotional Assessment differentiates frontotemporal dementia from depression. J Neurol Neurosurg Psychiatry 83(4):411-416. doi: 10.1136/jnnp-2011-301849 [10] Loas G, Corcos M, Stephan P, Pellet J, Bizouard P, Venisse JL, et al (2001) Factorial structure of the 20-item Toronto Alexithymia Scale: confirmatory factorial analyses in nonclinical and clinical samples. J Psychosom Res 50(5):255-261. doi:10.1016/s00223999(01)00197-0

[11] Collet L, Cottraux J (1986) The shortened Beck Depression Inventory (13 items). Study of the concurrent validity with the Hamilton scale and Widlöcher's retardation scale. Encephale 12(2):77-79.

[12] Spielberger C, Bruchon-Schweitzer M, Paulhan I (1993) Inventaire d'anxiété état-trait. Centre de psychologie appliquée 
[13] Cungi C, Bouhana S, Degoul G, Bibollet D (1997) Deux échelles brèves d'autoévaluation des stresseurs et du stress. http://www.cercle-d-excellence psy.org/fileadmin/Restreint/Stresseurs_Stress_echelle_Validation.pdf.

[14] Demers LA, Koven NS (2015) The Relation of Alexithymic Traits to Affective Theory of Mind. Am J Psychol 128(1):31. doi: 10.5406/amerjpsyc.128.1.0031

[15] Luyten P, Fonagy P (2016) An integrative, attachment-based approach to the management and treatment of patients with persistent somatic complaints. Improving Patient Treatment with Attachment Theory, eds J. Hunter and R. Maunder (Switzerland: Springer International Publishing), 127-144

[16] Llewellyn DJ, Lang IA, Langa KM, Huppert FA (2008) Cognitive function and psychological well-being: findings from a population-based cohort. Age Ageing 37:685-689. doi: 10.1093/ageing/afn194.

[17] Jongen PJ, Ruimschotel RP, Museler-Kreijns YM, Dragstra TMC, Duyverman L, Valkenburg-Vissers J (2017) Improved health-related quality of life, participation, and autonomy in patients with treatment-resistant chronic pain after an intensive social cognitive intervention with the participation of support partners. J Pain Res 10:2725-2738. doi: 10.2147/JPR.S137609 